\title{
Evaluation of quality of drinking water in Romania (science shops)
}

\author{
Norbert Steinhaus
}

\section{Context}

In Romania, most environmental problems, including deterioration of water source quality, have their origin in intensive industrialization and development of agriculture. Until 1990, there were no environmental protection policies/legislation/treatment facilities or accompanying measures in place. Until this case study, there were only a few studies on drinking water quality in the area. Those that existed were limited to questions of to what extent treatment in the treatment plants removed undesirable pollutants (especially those that might affect human health), or if the population was satisfied by the quality and quantity of water supplied.

Iasi underwent a rapid industrialization and population growth (from 180,000 inhabitants in 1980 to 349,000 in 2001). The demands for drinking and industrial water were filled through additional sources or sometimes by using a combination of water supplied by two or even three treated sources. Before 1990, it was quite frequent for some neighbourhoods to have interruptions to drinking water for eight hours a day.

Prior to the beginning of this project, no correlations had been made between the quality of water sources, the water treatment at the Water Works Company and the opinions and expectations of the residents. The research was designed for:

- subject status (age, occupation, income and family composition);

- drinking water quality (temperature, colour, taste, smell, solid impurities, turbidity, hardness). The questions related to quality were expressed as general particularities and not in scientific terms (persons were asked if they considered the water clear enough, although the associated indicator was turbidity);

- drinking water quantity (flow, pressure, continuous supply);

- use of alternatives (drinking water from other sources, mineral water, soft drinks, filter units at the tap); and

- other problems observed.

This project also focused on the evaluation of physical and chemical indicators, since they correlate with quality problems suggested by residents and are relevant for the calculation of efficiencies achieved at different stages of water treatment. As 
far as chemical indicators are concerned, a distinction was made between general characteristics and those that give information on priority pollutants and are of more concern for human health (toxic, carcinogenic or mutagenic properties).

The project lasted six months (June-November 1999). As this project was conducted through a Romanian science shop, all costs were supported from the MATRA Social Transformation Programme of the Dutch Ministry of Foreign Affairs, which provided seed funding to the science shops.

\section{Organization/structure}

A questionnaire was conceived for this study, and discussed with specialists in techniques of social inquiries from Alexandru Ioan Cuza and Gheorghe Asachi Technical universities in Iasi. Over 2,500 questionnaires were processed for the first part of the report regarding consultation with citizens. Face-to face interviews were used. For data collection and analysis, the following aspects were considered:

- Three sources of drinking water from different treatment plants were selected (two surface water sources and one underground source). The level of treatment per source is correlated with the influent water quality (less treatment for the underground source).

- A number of neighbourhoods accessing drinking water from the same treatment plant (source) were selected, to facilitate comparisons under similar conditions. There are neighbourhoods in Iasi supplied with drinking water from two treatment plants - mixtures.

- Objectivity of the interviewers (students) was assured by a brief training on inquiry techniques. Students had a specialization in environmental engineering, with basic knowledge of water quality indicators.

- Any other suggestions or problems that appeared with drinking water quality and quantity, as specified by the subjects, were registered separately in the same questionnaire, as observations.

- Several quality indicators were selected from the following groups of priority pollutants:

- volatile organic compounds generated in drinking water as secondary products, with disinfection by chlorine;

- non-volatile organic compounds;

- inorganic substances.

Water samples were taken from different points in the treatment process: raw water (inlet of the treatment plant); water from the reservoirs (after chlorination); or from the consumer (tap water), and these micro-pollutants were verified in a specialized laboratory in the Netherlands.

The results of these questionnaires, together with the analysis of quality indicators (physical and chemical) of treated water, served as a base for discussion of treatment technologies currently applied by the Water Works Company.

All of the data were computer processed using Excel, and presented graphically for each source. In all cases, the problems suggested by the participants in terms of 
both quality and quantity permitted a comparison of the sources. Students under the supervision of science shop coordinators contributed to the collection of raw data, analysis and interpretation.

Internal communication was maintained by regular meetings, phone, email and fax. Meetings were held with students, science shop staff, NGO representatives, Dutch participants in the MATRA project and Water Works Company staff.

The 1999 study was the pilot project of the newly founded science shop InterMEDIU (at the Technical University of Iasi) and is considered an illustration of the science shop approach for the study of a problem of interest to the whole community. No modification was necessary.

\section{Activities}

Quality indicators for toxic micro-pollutants were verified for the surface water sources. A correlation between the technical conditions and the degree of treatment was realized, and recommendations for improving the existent situation were given. A public debate on drinking water quality was organized, and representatives of the community (NGOs, neighbourhood associations), university staff and students, research institutes, governmental organizations (Environmental Protection Agency, City Hall representatives), Water Works Company and the media were invited.

The main results of the project referred to drinking water quality from different sources, as seen by the population and as demonstrated by available records or supplementary analysis. As somewhat expected, the interviewees considered the quality of drinking water supplied from the groundwater source, mainly seen as an alternative source for those living in other neighbourhoods, as good or very good.

Evaluation of quality indicators available at the Water Works Company or further verified by analysis proved that treatment achieved for surface water sources should be improved, either by increasing the removal efficiencies of each treatment step, or by upgrading the whole treatment plant. Several supplementary treatment steps or even alternatives to conventional processes have been proposed.

Recommendations included the necessity of a feasibility study, a cost analysis for treatment alternatives, and surveys of proposed modernization alternatives that will include public consultation. The report concretized all the findings and recommendations of the project. One hundred copies were published and distributed to governmental organizations, NGOs and to university students and staff.

The project received good media coverage, and for the students of the Environmental Engineering Department, it represented a very good opportunity to apply their knowledge related to treatment technologies; and an opportunity to learn more about the techniques of social inquiry, project management and computer applications.

Communication with the media was not always open and good. The media had access to the report, and representatives of all newspapers and local TV stations were invited to the public debate. The first project report in a local newspaper was not objective: it focused on the more sensational aspects of the report, with a 
view to boosting circulation figures, including the toxicity of water, which created some problems for participants involved in the project. At the public debate, the representative of the Water Works Company acknowledged they were aware that problems existed and they would make efforts to attract funds to improve drinking water quality.

The public debate was a good opportunity to mediate things; other articles and media coverage benefited from objective presentations. The project had an immediate and long-term use, internally and externally, and the project finding were made available for free. The department of Environmental Engineering and the Faculty of Industrial Chemistry appreciated the students' involvement in this science shop project. They agreed the continuation of their cooperation with science shop may contribute to a diploma or M.Sc. thesis. NGOs used the information both for NGO members and local community information. The Water Works Company used the report as evidence of the necessity of improving the quality of drinking water and modernizing the water treatment facilities, and to argue for these improvements in local development strategies.

The science shop used the report to promote science shop activities as an example of student participation, and also to raise public awareness about the quality of drinking water in Iasi. Subsequent proposals, in which the science shop was asked to participate, had water quality as a common theme. The project served as a basis for scientific publications and raised further technical questions. The project supervisor used the project information in a course, Water Treatment Technologies, for fourth-year students in Environmental Engineering.

Students participating in the project considered that there were many positive aspects to participation. In particular, they:

- used techniques of social inquiry and were able to get in contact with the community;

- had the opportunity to apply their knowledge (environmental engineering, drinking water technology) to a practical 'real' case;

- learned new skills in research methodology and the presentation of results and applied this to other scientific work;

- learned more about project and task management;

- improved computer and group communication skills;

- continued to cooperate with the science shop on other projects, including an international student project;

- considered the project a good starting point for future careers, including it in CVs/résumés.

The publication of a report without an ISBN was not considered a problem at that time, but resulted in use of the report without citation.

The project presented detailed information and rigorous methodology, with data that could be followed by the general public. For students, the main advantages were the opportunities for knowledge enhancement and improvement of communication and participative skills; the chance to work in larger groups of students was also appreciated. Students could now see aspects in practice they 
knew only in theory. Other aspects were the problem-based learning approach and cooperation in a less formal way, nevertheless going deeper into technical subjects.

For NGO representatives, the major benefit was the heightened level of awareness in the local community and among members of governmental organizations.

For the science shop staff, the project presented interest from the scientific and teaching point of view, and also innovative approach and linkages to societal issues.

Other positive aspects of the project included the organization and discussion of a public debate, and the involvement of students in a project for not only their technical background, but also their knowledge related to social inquiry techniques - part of the curricula, but not often applied. As the public debate was organized at the Faculty of Industrial Chemistry, with participation from other students and staff, this facilitated contact between specialists and NGO groups and represented good publicity for the faculty and the science shop.

The project resulted in additional collaborations between the NGO, other NGOs and government organizations. The science shop has not been involved in these but has continued to maintain contact with the NGO, sending them information about debates and calls for proposals.

Most interviewees considered the project a real success and not in need of improvement. However, providing information earlier to the media about project developments would have been helpful.

According to Carmen Teodosiu, of TU Iasi, InterMEDIU/science shop:

There were other Science Shop project proposals or further research on the topics (public involvement or drinking water treatment together with my diploma students). Other requests from NGOs to contribute to project proposals with subjects related to water pollution and awareness programs were received. The NGO that requested support for project proposal preparation, received funding to proceed with a survey and educational campaigns concerning the risk of nitrates and nitrites in the ground waters of Suceava plains, and the collaboration will continue in the period of project realization. (personal communication)

\section{Outcomes}

The science shop's neutral position between the public, local administration and university is considered useful for communities since it provides access to scientific research, information and education. The use of systematic methods, adequate presentation of results and the accessibility of project publications, as well as the affordability of science shop projects (until now, with no financial obligations for the NGOs), represent the possibility of connecting universities and communities through intermediaries such as science shops.

The science shop activities can bring specific contributions to the modernization of curricula and research at universities, i.e., through the use of flexible modules of learning/project-based learning, postgraduate courses, inclusion of science shop projects in regular teaching activity, multidisciplinary research (use of techniques of social inquiry or environmental and health assessments) and formulation of new project proposals. 
Important elements to the development of science shops activities in Romanian universities are:

- Official acknowledgement at the university/Ministry of Education level for these activities, the allocation of credit points for students, and staff time for supervision. For instance, the introduction of a course in project management and the facilitation of project work through the science shop or NGOs structures would allow students to gain more experience with practical projects and increase employment opportunities after graduation.

- Given the extent to which the opening of new perspectives and collaborative research with societal groups are priorities for universities, the support of science shop activities should be facilitated at least at the level of operational costs and adequate administrative rules.

- The development of other programmes through science shops (educational, postgraduate, professional training) can contribute to the broadening of the university focus and also provide supplementary funding.

- The visibility of science shop activities at the local level and the facilitation of international cooperation contribute indirectly to the image of faculties/ universities and thus needs adequate support from the university structures to improve outreach towards society organizations and the network of Romanian universities.

Science shop collaboration has particular features and advantages. The science shop is seen as a real, independent organization situated in a neutral position between the public, local administration and university, with the potential to benefit all participants. The advantages to cooperation with science shops are usually related to the experience, contacts, flexibility and communication of this approach, i.e., it can easily establish links with different departments. For example, the students received advice from specialists from the Department of Social Sciences at Alexandru Ioan Cuza and Gheorghe Asachi Technical universities in the development of the questionnaire.

For students, too, this type of connection presents an important opportunity. As one student said:

For me, as a student, it is important to have somebody from outside to help me get more information about aspects that we don't usually study in the faculty (project proposals, project management, presentations). I had the opportunity to learn more about this while working in the Science Shop. I think these organisations are more open to cooperation. (student respondent)

The experience of participants is also a very important factor to the success of a science shop project. In some cases this could be a challenge; however, in this project, all parties had sufficient knowledge and experience to ensure success.

In summary, this research model is successful because it presents a neutral view on the problem while offering a more flexible approach and the opportunity for many different groups to work together. Lastly, the enthusiasm that students brought to this project was key to its success. 